\title{
General thoracic surgery as a subspecialty in Colombia
}

\author{
Eric E. Vinck, MD
}

\footnotetext{
From the Department of Surgery, El Bosque University-Colombian School of Medicine, Bogotá, Colombia; Division of Thoracic Surgery Research, Cardioinfantil Foundation, Bogotá, Colombia; and Dr Horacio Oduber Hospitaal, Oranjestad, Aruba.

Disclosures: Author has nothing to disclose with regard to commercial support.

Received for publication Aug 12, 2018; revisions received Oct 1, 2018; accepted for publication Oct 7, 2018; available ahead of print Nov 15, 2018.

Address for reprints: Eric E. Vinck, MD, Cr 11 Cl 135c-18, Bogota, Colombia (E-mail: evinck518@gmail.com). J Thorac Cardiovasc Surg 2019;157:2542-6

$0022-5223 / \$ 36.00$

Copyright $(2) 2018$ by The American Association for Thoracic Surgery

https://doi.org/10.1016/j.jtcvs.2018.10.036
}

\section{BRIEF HISTORY OF GENERAL THORACIC SURGERY}

Chest surgery has come a long way from a single costal extraction to populate the earth to a procedure that resembles a video game. Thoracic surgery has been known since ancient times, however it was not until the past century that general thoracic surgery has become a separate surgical subspecialty. As this field of surgery has evolved, so has our knowledge of diseases we treat inside the chest.

At the beginning of the 20th century, the field of general surgery began expanding in response to the need for expertise in different areas of surgery. During the first half of the 20th century tuberculosis was the pathology most significant to the general thoracic surgeon. With this epidemic, along with World War I-related chest injuries, a special need for surgeons knowledgeable in thoracic diseases arose. Because of this need, general surgeons would begin dedicating their practice to thoracic pathologies., ${ }^{2,3}$ In 1909 Jacobaeus performed his famous thoracoscopy, this first important period in thoracic surgery was known as the era of enthusiasm. By 1914 tuberculosis was a worldwide pandemic and for some time it became the number one cause of death in Colombia. War and tuberculosis were the 2 main factors pivoting general thoracic from general surgery, although it was not foreign war but domestic armed conflict that required the Colombian general surgeon to start focusing on chest injuries. In 1914, Dr Pompilio Martínez performed the country's first cardiac suture because of a penetrating chest injury in Bogota. To answer to this new era of thoracic warfare injuries and tuberculosis, the American Association for Thoracic Surgery was created in $1917 .^{4-6}$ It is worth mentioning that the first surgery ever filmed was a general thoracic procedure by Dr Alejandro Posada in 1899 in Argentina. Because cardiovascular disease was not a major issue at this time, the need for 2 separate thoracic subspecialties was not necessary, and thus North America and Europe

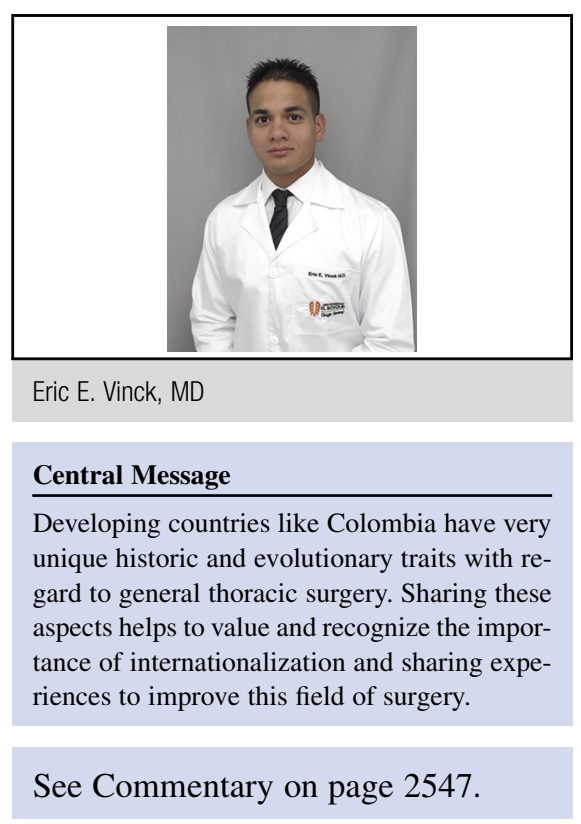

stuck to joint cardiothoracic surgery programs. As general thoracic surgery grew, new procedures were introduced like the first pneumonectomy performed by Evarts Graham in 1933; the first pneumonectomy in Colombia would be performed later in 1948 with the assistance of North American surgeons (Dr George Humphreys and others). ${ }^{1-7}$

During World War II, thoracic surgeons were once again challenged as they struggled to keep up with the complexity of chest injuries secondary to advancing modern warfare. During this second important period, the advent of antibiotics and chemotherapy began, treating most thoracic diseases, and general thoracic surgery was limited to thoracic trauma. At this same time cardiovascular disease began increasing and the need for cardiac surgeons spiked. Because of this sudden switch in chest disease prevalence, cardiac surgeons became more germane than general thoracic surgeons. By the 1940s leading programs maintained joint cardiothoracic residencies and to general thoracic surgery this was known as the era of neglect. ${ }^{2-8}$ Back in developing countries like Colombia, tuberculosis continued to be a problem despite antibiotics, and surgeons experienced in general thoracic surgery were still needed. During the second half of the 20th century and the years after World War II however, tuberculosis would be replaced by lung cancer as the pathology most treated by general thoracic surgeons; it became the 
number one cause of cancer deaths worldwide; Colombia was no exception. ${ }^{2-5}$ After World War II this steep increase in cardiovascular disease and lung cancer encouraged general thoracic and cardiac surgeons to keep their own area of care, once again calling for expertise from the general thoracic surgeon. In 1981, Dr Donald Paulson stated, "Failure to correct the imbalance in training of thoracic surgery has resulted in a vacuum, which could lead to disintegration of the specialty." A statement in response to the combined cardiothoracic surgery programs. ${ }^{2-4}$

\section{THE SUBSPECIALTY IN COLOMBIA}

Like North America, tuberculosis and trauma were the turning points that separated general thoracic from general surgery. Despite antibiotics, tuberculosis remained epidemic and continued domestic warfare required surgeons to maintain a specific focus on the chest. This necessity forced cardiac surgery into a different subspecialty and combining the 2 was never considered. To this day general thoracic and cardiovascular surgery are still 2 different subspecialties in Colombia.

By the 1960s, cardiac surgery in Colombia was already in development, and in the city of Medellin, general thoracic surgeries were performed by cardiac surgeons. In Bogota, however, thoracic surgeries were done by general surgeons who dedicated their practice to thoracic pathologies. Some surgeons acquired their thoracic surgical skills at programs from Chicago (Dr Gilberto Rueda) and Washington (Dr Camilo Schrader) through international/traveling fellowships, however, at this point there was still no official "thoracic surgery" subspecialty in the country. The health crisis in 1975 resulted in many physicians being left unemployed. Two years later in 1977, 24 of these affected physicians would go on to open their own medical school named "The Colombian School of Medicine." Although North America already had cardiothoracic programs established by the 1940s, it was not until 1988 that the Colombian health ministry recognized general thoracic surgery as an official subspecialty under this same medical school. ${ }^{2-9}$ In 1992 the first official thoracic surgery fellowship degree was given to Dr Leonidas Tapias. The first residency program director was $\mathrm{Dr}$ Fidel Camacho from its beginning in 1988 until his death in 2009. ${ }^{7,9,10}$ A second general thoracic surgery program was opened in 1992 at the National Cancer Center in Bogota. It was directed by Dr Camilo Schrader; these 2 programs would later fuse in 2004. Although the recognition of a general thoracic surgery subspecialty in Colombia came much later than in North America and Europe, it has evolved considerably. Some moments in the Colombian general thoracic surgery timeline worth mentioning are reported herein. Many of the firsts of general thoracic surgery took place in the city of Medellin. In 1985 Dr Alberto Villegas, a cardiovascular surgeon, performed the country's first heart transplants. He attained his cardiac surgery training at King's College University in England and later in Washington. In 1997, he performed the country's first successful lung transplant with his team of cardiovascular transplant surgeons. This was 34 years after the world's first lung transplant performed by Dr James Hardy in 1963. Although the first official lung transplant performed in Colombia was in Bogota in 1997, just months before Dr Villegas reported his first case in Medellin, the patient did not survive the procedure. ${ }^{10-12}$ In the early 1990s, a similar evolutionary trait Colombian general thoracic surgery shared with the rest of the world was videoassisted thoracoscopic surgery (VATS). Thoracoscopy in Colombia appeared around the same time as in other countries with the first reported cases in 1991 in Medellin. However, it was not until 2004 that VATS began to spread in Colombia after a young thoracic surgeon, Dr Juan Carlos Garzón, sought international VATS training in Hong Kong, and brought these techniques back to Colombia. ${ }^{13,14}$ In 2005 the country's first diaphragmatic pacemaker was placed by Dr Carlos Saldarriaga, also in Medellin; and the first case of robotic-assisted thoracic surgery in Colombia was performed by Dr Ricardo Buitrago in 2012. This would also be the first robotic-assisted thoracic surgery case in Latin America. In 2013 Dr Diego Gonzalez-Rivas visited Bogota and shared his uniportal VATS technique with Colombian thoracic surgeons, a technique he introduced in 2010, which is becoming a standard option for many patients in Colombia. Another milestone in thoracic surgery shared by Colombian surgeons and those from across the globe was subxiphoidal VATS, a technique begun in 2014. This same year in 2014, the first successful lung transplant in Bogota was performed by Dr Luis Téllez and Dr Juan Garzón. It is worth mentioning these 2 surgeons spent a considerable amount of time at Duke University's transplant department (considered by many to be the holy grail of general thoracic surgery) as part of an international/traveling fellowship training. At Duke, fundamental transplant techniques and skills were brought back, which to this day guide lung transplantation at the Cardioinfantil Foundation in Bogota. In 2016 Téllez and Garzón would report the first cases of antiarrhythmic bilateral sympathectomies for refractory arrhythmias secondary to Chagas disease; this initial series was reported in association with the University of California, Los Angeles. ${ }^{15}$ Table 1 shows a summary of events in the history of thoracic surgery.

\section{THE PROGRAM AND TRAINING YOUNG SURGEONS}

Today, Colombia has a single general thoracic surgery program under the same medical school it began, compared with 6 cardiovascular surgery programs across the country. This fellowship is based in Bogota at the Santa Clara 
TABLE 1. Thoracic surgery timetable in Colombia

\begin{tabular}{|c|c|c|}
\hline Year & Milestone & City \\
\hline 1914 & First cardiac suture & Bogota \\
\hline 1948 & First pneumonectomy & Bogota \\
\hline 1960 & $\begin{array}{l}\text { Thoracic surgeries by } \\
\text { nonthoracic surgeons }\end{array}$ & Bogota and Medellin \\
\hline 1985 & First heart transplantation & Medellin \\
\hline 1988 & $\begin{array}{l}\text { Health Ministry } \\
\text { recognizes thoracic } \\
\text { surgery }\end{array}$ & Bogota \\
\hline 1990 & $\begin{array}{l}\text { El Bosque University } \\
\text { opens the Thoracic } \\
\text { Surgery Program }\end{array}$ & Bogota \\
\hline 1991 & $\begin{array}{l}\text { First thoracoscopic } \\
\text { procedures }\end{array}$ & Medellin and Bogota \\
\hline 1992 & $\begin{array}{l}\text { First thoracic surgery } \\
\text { degree }\end{array}$ & Bogota \\
\hline 1997 & First lung transplantation & Medellin \\
\hline 2004 & $\begin{array}{c}\text { Video-assisted thoracic } \\
\text { surgery lobectomies }\end{array}$ & Bogota \\
\hline 2005 & $\begin{array}{l}\text { First diaphragmatic } \\
\text { pacemaker }\end{array}$ & Medellin \\
\hline 2012 & $\begin{array}{l}\text { First robotic thoracic } \\
\text { surgery }\end{array}$ & Bogota \\
\hline 2014 & $\begin{array}{l}\text { First lung transplantation } \\
\text { in Bogota }\end{array}$ & Bogota \\
\hline 2016 & $\begin{array}{l}\text { First cases of } \\
\text { antiarrhythmic video- } \\
\text { assisted thoracic } \\
\text { surgery sympathectomy }\end{array}$ & Bogota \\
\hline 2018 & $\begin{array}{l}\text { The Thoracic Surgery } \\
\text { Program graduates } \\
\text { surgeon } 57\end{array}$ & Bogota \\
\hline
\end{tabular}

Hospital where tuberculosis continues to be treated medically and surgically. This 2-year residency program accepts national as well as international candidates. Prerequisites include being a graduated general surgeon whether nationally or internationally. In Colombia the general thoracic residency program as well as the cardiovascular surgery programs are designed as subspecialties of general surgery and are directed toward general surgeons; integrated programs from medical school and joint cardiothoracic tracks do not exist.

General surgeons may apply after completing a 4-year (Latin America) or a 5- to 6-year (Europe/Unites States) general surgery training program. After passing the written admissions exam ( $80 \%$ passing rate), interviews are conducted and 2 residents are chosen per year; approximately 10 general surgeons apply yearly. During the interviews candidates are accepted according to exam results, general surgery experience, publications, and English-speaking skills. On average 1 international candidate applies every 2 years. During the 2-year training program, residents/fellows rotate through different types of hospitals, these include trauma centers, tertiary care facilities, oncology hospitals, and lung transplant departments. Residents are also encouraged to choose elective rotations outside of Colombia to broaden their knowledge of general thoracic surgery. Attractive international rotations include Brazil, Argentina, Spain, and of course the United States. Other international/traveling fellowship sites at which young thoracic surgeons have trained include Sweden (Dr Stella Martínez). Throughout the 2-year training, residents are assessed at the end of every rotation (about every 4 months) with a written exam as well as demonstration of clinical knowledge and surgical skills. The extent of responsibilities and surgical independence granted to residents depend on individual abilities. Surgeries vary according to each training center. In general, the procedure distribution includes $30 \%$ VATS resections, $20 \%$ pleural surgeries, $20 \%$ infectious disease surgeries, $10 \%$ thoracic wall procedures, $10 \%$ tracheal, $5 \%$ esophageal, and $5 \%$ others.

The general thoracic surgery degree is given upon successful completion of the requirements established by the Colombian School of Medicine. For international general surgeons, after having completed the general thoracic surgery training in Colombia, they must obtain their Colombian medical license from the health ministry if they wish to practice in the country. For Colombian general surgeons, this degree is registered by health ministry and allows the young thoracic surgeon to commence practice unsupervised anywhere in the country. However, a 6-month supervised postgraduate fellowship is recommended. For young/ recently graduated thoracic surgeons finding practicing spots is not difficult considering a current shortage of general thoracic surgeons in the country. Some important professors of thoracic surgery include Dr Mario López, Luis García-Herreros, Andres Jiménez, Rodolfo Barrios, and Rafael Beltrán. Table 2 shows a summary of the thoracic surgery program.

The program has been around for 28 years now, at the moment under the direction of Dr Stella Martínez, the second director in the program's history since 2009. Dr Stella Martínez was not only the first female thoracic surgeon in Colombia but also the only female thoracic surgeon in Colombia for 9 years until Dr Anastasia Ferro completed her training in 2004. Despite many challenges, the fierceness of Dr Martínez has been critical in the growth of thoracic surgery in Colombia. At the moment, 72 general thoracic surgeons are currently active in Colombia, 57 of them having graduated from this program. Despite having a single fellowship program, the number of applicants to general thoracic surgery training in Colombia remains low. Initially it was thought to be because of the lack of resident reimbursement. In Colombia, all residencies and 
TABLE 2. General Thoracic Surgery Program characteristics, El Bosque University

\begin{tabular}{|c|c|}
\hline Characteristic & Description \\
\hline Duration & 2 Years \\
\hline Location & Bogota \\
\hline Prerequisite training & General surgery \\
\hline Reimbursements & None \\
\hline Rotations & $\begin{array}{l}4 \text { Different hospitals/clinics, } \\
\text { international elective rotations are } \\
\text { available }\end{array}$ \\
\hline Evaluation & $\begin{array}{r}\text { Written (every 3-4 mo), clinical } \\
\text { knowledge and surgical skills }\end{array}$ \\
\hline $\begin{array}{l}\text { Independence and } \\
\text { responsibility }\end{array}$ & $\begin{array}{l}\text { According to individual abilities and } \\
\text { knowledge }\end{array}$ \\
\hline Title & General Thoracic Surgeon \\
\hline $\begin{array}{l}\text { Board certification } \\
\text { and license }\end{array}$ & $\begin{array}{l}\text { Colombian graduates may begin } \\
\text { practice upon completion; } \\
\text { international residents must obtain } \\
\text { their Colombian Medical License } \\
\text { to practice }\end{array}$ \\
\hline $\begin{array}{l}\text { Finding practice when } \\
\text { training completed }\end{array}$ & Spots available—current deficit \\
\hline
\end{tabular}

fellowships are without reimbursement; the Colombian health ministry is currently working on this problem. Another possible explanation is that cardiac surgery still overshadows general thoracic surgery. Whichever the case, initiatives are being taken to generate as much interest in young candidates as possible. This is not only important to the program itself but to the country as a whole. In relation to the Colombian population, there is a current deficit of approximately 25 thoracic surgeons; a shortage also experienced in other parts of the world.

\section{ORGANIZATION AND INTERNATIONALIZATION}

Although the Colombian Society of Pneumology and Thoracic Surgery has officially existed since 1954, for more than 3 decades it focused primarily on nonsurgical pulmonary medicine. Today, this association has a stronger thoracic surgery involvement and organizes and monitors general thoracic surgery across the country. The Colombian Society for Thoracic Surgery also works with the Latin American Thoracic Association; organizing annual congresses, committees, and other similar activities that encourage interactions between residents/fellows and allow research opportunities. Some thoracic surgeons also work individually with the Ibero American Association of Thoracic Surgery, propelling international relations. The Colombian thoracic surgery residency program itself is based in Bogota and holds monthly meetings where complex cases, surgical discussions, sociodemographic aspects of thoracic surgery, and advances are presented and discussed. At these meetings, fellows/residents present research developments, literature reviews, and other lectures. Despite the overall advances in thoracic surgery in Colombia, one area with room for growth is research. Although clinical research is encouraged and performed at the different rotation centers, multicenter and randomized trials are still in development and in their infancy. However, with a generation of younger residents, advancing technologies, and an increasing interest in traveling fellowships, we hope that a new wave in research will arise.

It is imperative to recognize the importance and the role international/traveling fellowships have played in the development and training of general thoracic surgery and surgeons in Colombia throughout history, especially with regard to oncological resections. Since the first pneumonectomy in the late 1940s, to lung transplantation and contemporary minimally invasive techniques learned from high-ranking North American schools, the skill and knowledge acquisition from international pioneers of thoracic surgery have been and will continue to be vital.

\section{CONCLUSIONS}

The history of general thoracic surgery in Colombia has had similarities and differences with North American and European chest surgery, mostly in timeline. Understanding the challenges and limitations from being a third-world country, we continue learning and improving our skills following North American and European recommendations and guidelines as well as sharing our experiences with other countries such as rare cases like the paradoxical pneumothorax reported by Dr García-Herreros in $2018 .{ }^{16}$ Although general thoracic and cardiac surgeons keep on working side by side, not forgetting the "cardiothoracic" history of the first lung transplant, there is no doubt that this "general thoracic" subspecialty will keep on growing in Colombia and answering to the increasing demand placed by lung cancer and chest trauma. At the same time, remembering the importance of international training, and responsibility to patients who need experts in this field. The current worldwide deficit of thoracic surgeons will also continue to be addressed through raising interest in young surgeons to choose a career in this wonderful subspecialty.

\section{References}

1. Walcott-Sapp S, Sukumar MS. A history of thoracic drainage: from ancient Greeks to wound sucking drummers to digital monitoring. Available at: https://www.ctsnet. org/article/history-thoracic-drainage-ancient-greeks-wound-sucking-drummersdigital-monitoring. Accessed November 12, 2018.

2. Paulson DL. A time for assessment. J Thorac Cardiovasc Surg. 1981;82:163-8. 3. Pearson FG. Adventures in surgery. J Thorac Cardiovasc Surg. 1990;100:639-51.

4. He J. History and current status of mini-invasive thoracic surgery. J Thorac Dis. 2011;3:115-21.

5. Smith RA. Development of lung surgery in the United Kingdom. Thorax. 1982; 37:161-8.

6. Ordóñez SA, López FA. Tuberculosis in Colombia, from the history to the understanding of the disease. MedUNAB. 2014;16:127-42.

7. Campos HR. Historia de la cirugía de tórax en el Hospital Universitario San Ignacio. Rev Colomb Neumologia. 2012;24:51-3. 
8. Smith PK, Mulvihill MS. The history of Duke thoracic surgery. Semin Thorac Cardiovasc Surg. 2015;27:360-9.

9. Luh SP, Liu HP. Video-assisted thoracic surgery - the past, present status and the future. J Zhejiang Univ Sci B. 2006;7:118-28.

10. Olaya L, Olaya C, Martinez S, Matyas R, Gordillo M, Daza E, et al. Historia del primer trasplante de pulmon en Colombia. Rev Colomb Cardiol. 1999;7: 443-9.

11. Villegas A. Trasplante de pulmón. Una opción para pacientes con enfermedad pulmonar terminal. Rev Colomb Cardiol. 1998;6:339-46.

12. Hardy JD. The first lung transplant in man (1963) and the first heart transplant in man (1964). Transpl Proc. 1999;31:25-9.
13. Garzon JC, Ng CS, Lee TW, Yim AP. Video-assisted thoracic surgery lung resection after endobronchial valve placement. J Thorac Cardiovasc Surg. 2006;131:499-500.

14. Garzon JC, Ng CS, Sihoe AD, Manlulu AV, Wong RH, Lee TW, et al. Video-assisted thoracic surgery pulmonary resection for lung cancer in patients with poor lung function. Ann Thorac Surg. 2006;81:1996-2003.

15. Saenz LC, Corrales FM, Bautista W, Traina M, Meymandi S, Rodriguez DA, et al. Cardiac sympathetic denervation for intractable ventricular arrhythmias in Chagas disease. Heart Rhythm. 2016;13:1388-94.

16. Garcia-Herreros LG, Villamizar E, Salcedo DF. Trans-mediastinal herniation of pulmonary bulla with paradoxical pneumothorax. J Surg Case Rep. 2018;2018: rjy 174 . 